\title{
O ensino remoto em Minas Gerais: uma análise pelo ciclo de políticas
}

\author{
Emergency remote teaching in Minas Gerais: a policy cycle analysis
}

Enseñanza remota de emergencia: en Minas Gerais: un análisis del ciclo de políticas

\author{
Cláudio Lúcio Mendes ${ }^{1}$ \\ Tielle Alves Souto ${ }^{2}$
}

\begin{abstract}
Resumo
Este artigo trata do Ensino Remoto Emergencial (ERE) proposto em consequência da pandemia de SARS-CoV-2, focando-se no programa Regime Especial de Atividades Não Presenciais (REANP) para a Educação Básica apresentado pelo governo do estado de Minas Gerais. O objetivo do estudo é compreender o cenário do ensino remoto e as possíveis dificuldades relacionadas à sua viabilização e ao seu funcionamento, em especial porque recomendou-se uma soma de esforços para o emprego de mecanismos on-line, televisivos, radiofônicos e/ou impressos. Com o intuito de cumprir o objetivo, inspirou-se teóricometodologicamente na noção de ciclo de políticas de Stephen Ball. Analiticamente, refletiu-se sobre o contexto de influência proposto por Ball que, no caso do REANP, foi fortemente produzido em consequência às condições sanitárias e ao isolamento social. Tratou-se também dos contextos da produção de texto - relacionando o cenário mineiro com o nacional para a elaboração textual do REANP - e da prática - trazendo aspectos sobre acesso às tecnologias digitais, condições de trabalho, realidades sociais e divulgação de informações por meios online sobre o que é o REANP e suas possíveis interpretações em realidades locais. Ao se analisar o REANP a luz do ciclo de políticas, concluiu-se duas coisas: 1) o ensino escolar já apresentava dificuldades que aumentaram durante a pandemia, ficando gritantes as relacionadas à formação de professores, à valorização da profissão docente e às condições materiais para o trabalho com as tecnologias digitais; 2) no pós-pandemia, se as políticas educacionais continuarem a dar a mesma atenção periférica a tais dificuldades, os problemas sociais, políticos e de ensino tenderão a se tornar mais agudos.
\end{abstract}

Palavras-chave: Política educacional; Ensino remoto emergencial; Ciclo de políticas; Pandemia; Tecnologias digitais.

\footnotetext{
${ }^{1}$ Doutorado em Educação pela UFRGS. Professor Associado do Departamento de Educação da Universidade Federal de Lavras, atuando como pesquisador da área de Educação, Neurociência e Tecnologia e professor do Mestrado em Educação Profissional da UFLA. Coordenador do Grupo de Estudo, Pesquisa e Extensão de Educação e Neurociência (ENE). E-mail: claudio.mendes@ufla.br ORCID: http://orcid.org/0000-0001-6114-0566

${ }^{2}$ Aluna do Mestrado do Programa de Pós-Graduação em Educação da Universidade Federal de Lavras (UFLA)-Lavras-MG-Brasil . E-mail: tiellealves@yahoo.com.br. ORCID: http://orcid.org/0000-0002$\underline{7551-7077}$
} 


\begin{abstract}
This article deals with the Emergency Remote Teaching (ERT) proposed in consequence of the SARS-CoV-2 pandemic, focusing on the Special Scheme of Non-Presential Activities (REANP) program for students from 3 to 14 years old presented by the state government of Minas Gerais. The objective of the study is to understand the emergency remote teaching scenario and the possible difficulties related to its feasibility and operation, especially since it recommended a sum of efforts for the use of online, television, radio and/or printed mechanisms. In order to fulfill the objective, the theoretical and methodological inspiration was Stephen Ball's notion of policy cycle. Analytically, we reflected on the context of influence proposed by Ball that, in the case of the REANP, was strongly produced as a result of sanitary conditions and social isolation. It also addressed the contexts of textual production - relating the Minas Gerais scenario to the national one for the textual elaboration of REANP - and of practice - bringing aspects about access to digital technologies, working conditions, social realities and dissemination of information through the Internet about what is REANP and its possible interpretations in local realities. In analyzing the REANP in light of the policy cycle, two things were concluded: 1) school teaching already had difficulties that increased during the pandemic, with the most obvious being those related to teacher training, valuing the teaching profession, and the material conditions for working with digital technologies; 2) in the post-pandemic, if educational policies continue to give the same peripheral attention to such difficulties, social, political, and teaching problems will tend to become more acute.
\end{abstract}

Keywords: Educational policies; Emergency remote teaching; Policy cycle; Pandemic; Digital technologies.

\title{
Resumen
}

Este artículo trata del Enseñanza Remota de Emergencia (ERE) propuesto como consecuencia de la pandemia de SARS-CoV-2, centrándose en el Programa de Actividades Especiales No Presenciales (REANP) para niños de 3 a 14 años presentado por el gobierno del estado de Minas Gerais. El objetivo del estudio es comprender el escenario de la enseñanza a distancia y las posibles dificultades relacionadas con su viabilidad y funcionamiento, especialmente porque se recomendó una suma de esfuerzos para el uso de Internet, televisión, radio y/o mecanismos impresos. Para cumplir el objetivo, la inspiración teórica y metodológica se basó en la noción de ciclo político de Stephen Ball. Analíticamente, reflexionó sobre el contexto de influencia propuesto por Ball que, en el caso de REANP, se produjo fuertemente como consecuencia de las condiciones sanitarias y el aislamiento social. También abordó los contextos de producción de textos - relacionando el escenario de Minas Gerais con el nacional para la elaboración textual de REANP - y la práctica - trayendo aspectos de acceso a tecnologías digitales, condiciones de trabajo, realidades sociales y difusión de información a través de medios online sobre qué es REANP y sus posibles interpretaciones en las realidades locales. Al analizar el REANP a la luz del ciclo político, se concluyeron dos cosas: 1) la educación escolar ya presentaba dificultades que se incrementaron durante la pandemia, quedando patentes las relacionadas con la formación del profesorado, la valorización de la profesión docente y las condiciones materiales para trabajar con las tecnologías digitales; 2) en la post-pandemia, si las políticas educativas siguen prestando la misma atención periférica a estas dificultades, los problemas sociales, políticos y educativos tenderán a agudizarse.

Palabras clave: Políticas educativas; Enseñanza remota de emergencia; Ciclo de políticas; Pandemia; Tecnologías digitales. 


\section{Introdução}

O estudo sobre políticas e programas públicos para o uso das tecnologias digitais na educação já vem sendo realizado há alguns anos ${ }^{3}$. No entanto, o cenário pandêmico modificou nossas abordagens, acelerando de diversas maneiras o emprego dessas tecnologias e as políticas que as envolvem. A pandemia causada pelo novo coronavírus (SARS-CoV-2) que se iniciou no Brasil em 2020, trouxe consigo, além de incertezas em relação à saúde e outros setores, uma inquietação na educação. Tal inquietação está relacionada aos desafios que a educação teria em relação ao distanciamento social e como o ensino seria desenvolvido (SAMPAIO, 2020). Em diversos cenários, recomendou-se uma soma de esforços para que gestores da educação criassem ou reforçassem, dentro de suas condições e possibilidades, plataformas de aulas on-line em todos os níveis de ensino. Nessa lógica, a solução inicial encontrada foi o Ensino Remoto Emergencial (ERE) ${ }^{4}$ - que nas unidades da federação assumiu diversos nomes na Educação Básica -, apoiando-se em mecanismos on-line, televisivos, radiofônicos e/ou impressos (estes últimos, entregues aos estudantes pelos mais

\footnotetext{
${ }^{3}$ A política educacional no Brasil, como um campo acadêmico de estudo, vem se estruturando "desde o final da década de 1960, com a criação de associações científicas como a ANPAE (1961), com a utilização mais frequente do termo 'política educacional' em publicações e em documentos oficiais e com a implantação da Pós-Graduação (1965) e do primeiro mestrado em Educação (PUC-Rio, 1966)" (STREMEL; MAINARDES, 2019, p. 36), tratando dos mais diversos temas nas áreas de administração da educação, políticas públicas, educação comparada e algumas outras. De maneira um pouco marginal a esse movimento e de modo mais recente, podemos considerar que as análises dos programas e das políticas educacionais sobre o emprego das tecnologias digitais começaram na década de 1980, no mesmo momento que as próprias tecnologias digitais começaram a ser propostas para o emprego educacional e, mais especificamente, escolar (ALMEIDA; VALENTE, 2016).

${ }^{4}$ Pelo que conseguimos rastrear, o termo Ensino Remoto Emergencial (emergency remote teaching ERT - em inglês) foi empregado pela primeira vez no início de 2020 em grupos de mídias sociais de professores que trabalham com educação e tecnologia em universidades norte-americanas, caracterizando "uma mudança temporária de ensino [presencial, EAD, on-line ou híbrido] para um modo de ensino alternativo devido a circunstâncias de crise. Envolve o uso de soluções de ensino totalmente remotas que, de outra forma, seriam ministradas presencialmente ou como cursos combinados ou híbridos e que retornariam a esse formato assim que a crise ou emergência diminuísse. O objetivo principal, nessas circunstâncias, não é recriar um ecossistema educacional robusto, mas, sim, fornecer acesso temporário à instrução e aos suportes instrucionais de uma maneira que seja rápida de configurar e esteja disponível de forma confiável durante uma emergência ou crise" (HODGES et al, 2020, s./p.).
} 
diversos meios) (RONDINI et al, 2020; CASTIONI et al, 2021). Com esse cenário vieram igualmente os desafios aos professores, aos alunos e às famílias.

Diante de tais questões, torna-se central compreender como políticas e programas públicos estão sendo modificados, repensados e, em especial, propostos para enfrentar essas dificuldades e necessidades. Não podemos esquecer que são nas políticas e nos programas que se configuram iniciativas - tanto antes, durante e após pandemia - interessadas em: 1) estabelecer diálogos entre os componentes curriculares e o letramento midiático e informacional; 2) elaborar as propostas às escolas e aos professores no enfrentamento às incertezas advindas do uso de tecnologias com intencionalidades pedagógicas acerca do desenvolvimento dos estudantes (ALMEIDA; VALENTE, 2016). Nesse cenário, uma questão nos instiga: quais políticas e programas educacionais vêm sendo propostos com o intuito de desenvolver processos de ensino e aprendizagem significativos e possíveis de serem realizados de maneira remota? O presente texto busca apontar medidas adotadas para reordenar e reorganizar o ensino e a aprendizagem - a partir da noção de ERE - apresentadas pelo governo do estado de Minas Gerais por meio do Regime Especial de Atividades Não Presenciais (REANP) focado na Educação Básica.

O objetivo do estudo é compreender o cenário do ensino remoto emergencial e as possíveis dificuldades atreladas à sua viabilização e ao seu funcionamento. Com o intuito de cumprir tal objetivo, nos inspiramos na noção de ciclo de políticas de Stephen Ball. Com a intenção de compreender como essas dificuldades foram (ou não) sanadas, realizou-se uma análise nos materiais/ferramentas disponibilizados pela Secretaria de Estado de Educação de Minas Gerais (SEE/MG). No desenvolvimento do texto, na próxima seção trataremos do ciclo de políticas de Ball, descrevendo os cinco contextos que a compõe e justificando os motivos de nos concentrarmos em três deles: de influência, da produção de texto e da prática. $\mathrm{Na}$ terceira seção, refletimos acerca do contexto de influência que, no caso do REANP, foi fortemente produzido em consequência às condições sanitárias e ao isolamento social. $\mathrm{Na}$ seção seguinte, trataremos dos contextos da produção de texto - relacionando o cenário mineiro com o nacional para a elaboração textual do REANP - e da prática - trazendo aspectos anteriores à pandemia no tocante às tecnologias digitais, bem como aspectos contemporâneos sobre condições de trabalho, realidades sociais e divulgação de informações 
por meios on-line explicando o que é o REANP e suas possíveis interpretações em realidades locais. Por último, apresentamos nossas considerações finais.

\section{O ciclo de políticas de Ball}

Partimos do princípio que o enfoque do ciclo de políticas, inicialmente formulado por Ball e Bowe - com contribuições posteriores de Anne Gold e outros autores - pode auxiliar em uma melhor compreensão e apreciação de como se desenvolvem as estratégias e as trajetórias das políticas e programas públicos educacionais. Consideramos que é "um referencial útil para a análise de programas e políticas educacionais", podendo ser empregado na apreciação crítica da "trajetória dos mesmos, desde sua formulação inicial até a sua implementação no contexto da prática e seus efeitos" (MAINARDES, 2006, p. 48). Além disso, o "ciclo de políticas focaliza a formação do discurso de uma política, a implementação dos sujeitos com enfoque nos processos micropolíticos e a ação dos profissionais que lidam com elas no contexto da prática" (MAINARDES; MARCONDES, 2009, p. 48). Nesse sentido, podemos investigar o processo sendo desenvolvido e direcionado às políticas em educação, envolvendo os agentes que participam de suas proposituras e implementações, incluindo aqueles que sofrerão seus efeitos, colocando em prática tais políticas e como elas podem ser reinterpretadas.

Inicialmente, a abordagem do ciclo de políticas foi formulada por Stephen Ball e Richard Bowe (1992, p. 100) considerando que ao se "pesquisar o ambiente escolar exige-se que consideremos não apenas o Currículo Nacional" - no nosso caso, a Base Nacional Comum Curricular (BNCC) e/ou as propostas curriculares dos entes federativos -, "mas também como os vários atores escolares interpretam a Lei, como se faz a gestão local das escolas", além de levar em conta "os processos de capacitação realizados por diferentes órgãos, grupos e indivíduos de diversas formas". Nesse sentido, o ciclo de políticas configurava-se em um método focado na análise de políticas, não dizendo respeito unicamente à explicação do que elas são. Assim "o ciclo de políticas não tem intenção de ser uma descrição" pura e simples das políticas. É, acima de tudo "uma maneira de pensar sobre elas e saber como as mesmas são feitas” (MAINARDES; MARCONDES, 2009, p. 305). Ball e Bowe (1992) tentaram caracterizar o processo político - nessa configuração primária, ainda 
de maneira muito amarrada e fixa -, introduzindo um ciclo contínuo constituído por três facetas sequenciadas e temporalmente separadas: 1) política proposta, referindo-se "à política oficial, relacionada com as intenções [...] do governo" suas estruturas de poder, especialmente o legislativo e os órgãos de educação, e "também [as] intenções das escolas, autoridades locais e [de] outras arenas onde as políticas emergem"; 2) política de fato, basicamente centrando-se nos "textos políticos e textos legislativos que dão forma à política proposta"; 3) política em uso, tratando-se dos "discursos e [das] práticas institucionais que emergem do processo de implementação das políticas pelos profissionais que atuam no nível da prática" (MAINARDES, 2006, p. 49).

Logo após, na busca de avançar e superar a rigidez e ambiguidade da primeira configuração, ampliando as análises da variedade de intenções e disputas no processo político, Bowe, Ball e Gold (1992) propuseram uma outra configuração, não apresentando divisão temporal ou sequencial, na tentativa de superar um tipo de análise feito por etapas lineares. Essa nova configuração constituiu-se por três contextos: o contexto da influência, o contexto da produção do texto e o contexto da prática. O contexto da influência é aquele que geralmente as políticas públicas são iniciadas e os discursos construídos, sendo "nele que grupos de interesse disputam para influenciar a definição das finalidades sociais da educação, sendo as redes sociais uma atuante dentro e em torno de partidos políticos, do governo e de processos legislativos" (MAINARDES, 2006, p. 51). Podemos concluir que é nesse contexto que os conceitos adquirem legitimidade legal e normativa e formam os discursos que dão base às políticas.

Já no "contexto da produção de texto, os textos políticos comumente estão ligados a linguagem do interesse público, e não são necessariamente [transparentes] e coerentes" em sua argumentação e fundamentação científica, "podendo ser também [narrativamente] contraditórios", atendendo a noções ideológicas de grupos organizados ou de interesses morais, religiosos ou fundamentalistas (MAINARDES, 2006, p. 52). Sendo assim, podemos entender que políticas são intervenções textuais, carregando limitações materiais e possibilidades. O texto, no entanto, é apenas uma pequena parte (porém, uma parte importante) da produção, sendo empregado "para indicar que as políticas são interpretadas e materializadas de diferentes e variadas formas. Os atores envolvidos (no caso, os professores) têm o controle do processo e não são 'meros implementadores' das políticas” (MAINARDES; 
MARCONDES, 2009, p. 315). As respostas desse contexto têm consequências reais, e elas são vivenciadas no terceiro contexto, o da prática, na qual as políticas ganham sentido.

O contexto da prática evidencia a "política em ação, [salientando] a política sendo submetida a interpretações e recriações pelos atores locais" (professores, gestores e comunidades). Dessa maneira, políticas pensadas em outros contextos "podem sofrer mudanças e transformações significativas, inclusive serem recriadas" (LIMA et al, 2018, p. 4). O ponto importante nisso reside no protagonismo assumido pelos profissionais que estão na escola, considerando-se para análise o que acreditam e pensam. Nessa perspectiva, o ciclo conduz a um tipo de análise que permite contemplar o espaço escolar como um local de criação e recriação das políticas oficiais. Também é importante "verificar e compreender as rearticulações e embates que se processam em cada um dos contextos desde onde a política é gestada, passando pela produção do texto até sua chegada ao local onde os agentes a vivenciam" (MAINARDES; GANDIN, 2013, p. 150).

Após outras discussões, ponderações, experimentações em pesquisas e críticas recebidas, Ball (1994) amplia e refina a noção de ciclo de políticas com dois outros contextos: o dos resultados e o da estratégia política. Com o contexto dos resultados - uma espécie de alongamento ou refinamento do contexto da prática -, a preocupação está em se pensar os impactos ou efeitos relacionados às "interações com as desigualdades existentes" (MAINARDES, 2006, p. 54). Ball (1994) não está tratando da relação de causa e efeito, especialmente porque muitas vezes só procuramos quais foram as causas quando tomamos ciência de seus efeitos (ROSE, 1996). Ele traz a ideia do efeito no sentido foucaultiano, buscando identificar que papel as práticas desempenham, com o intuito de "analisar [...] o que as práticas fazem" (DREYFUS; RABINOW, 1995, p. 135), sem dar atenção à noção de origem que a busca da causa carrega. Efeito, então, seria a descrição da expressão de como as práticas políticas gerais (propostas ou em consequência do REANP) e localizadas (por exemplo, as propostas e os usos feitos de uma mesma proposta por um grupo de professores em uma determinada escola) são "organizadas [e em conjunto] operam" tanto de maneira ampla como específica (DREYFUS; RABINOW, 1995, p. 115). Assim, a abordagem dos efeitos, gerais e específicos, "sugere-nos que a análise de uma política" educacional envolve investigar as suas "várias facetas[,] dimensões [e] implicações (por exemplo, a análise das mudanças e do impacto em/sobre currículo, pedagogia, avaliação e organização) e [as suas] 
interfaces [...] com outras políticas setoriais e com o conjunto das políticas" (MAINARDES, 2006, p. 54-55).

O contexto de estratégia política busca, da mesma forma, articular cenários de micropolítica com de macropolítica, objetivando a "identificação de um conjunto de atividades sociais e políticas que seriam necessárias para lidar com as desigualdades criadas ou reproduzidas pela política investigada”. Assim, relacionada centralmente ao contexto da influência, as estratégias políticas gerais e locais devem ser levadas em conta ao se tratar dos "embates e situações sociais específicos" (MAINARDES, 2006, p. 55), nacionais e globais envolvidos em políticas educacionais. Nesse sentido, as políticas não são simplesmente implementadas de maneira estratégica, seguindo o ordenamento posterior a sua elaboração e promulgação. Nos espaços de micropolítica, as políticas educacionais, muitas vezes, "são ignoradas, dispensadas ou esquecidas, e isto porque a prática é sempre contingente, complexa e instável" (ROSA, 2019, p. 8). Como esses aspectos eram, em parte, marginalizados na primeira elaboração, vem daí igualmente a direção escolhida por Ball ao refinar sua noção de ciclo de políticas, procurando trazer aos escopos de análises a ideia de que as "políticas estarão sempre sujeitas à erosão e ao enfraquecimento de suas bases, por efeito da ação 'encarnada' das pessoas que são seu objeto" (BALL, 1994, p. 10-11). Entendemos que Ball nos oferece uma caixa de ferramentas para analisar as políticas educacionais, não "uma teoria totalizante que nos diz como o mundo funciona" (MAINARDES; MARCONDES, 2009, p. 313). De qualquer forma, esses mesmos autores nos lembram que

o contexto dos resultados/efeitos é uma extensão do contexto da prática (infraestrutura disponível, culturas profissionais, processos de interpretação e tradução, pressões externas etc.). Já o contexto da estratégia política está relacionado ao contexto da influência, uma vez que integra o processo pelo qual as políticas são mudadas (MAINARDES; MARCONDES, 2009, p. 306).

Neste texto, trabalharemos dando atenção aos contextos da produção de texto, de influência e da prática (re)configurados no contexto pandêmico. Entendemos que "a abordagem do ciclo de políticas traz várias contribuições para a análise de políticas, uma vez que o processo político é entendido como multifacetado e dialético, necessitando articular as perspectivas macro e micro" (MAINARDES, 2006, p. 55). Não negamos, com base na literatura, que os cinco contextos "estão inter-relacionados", não tendo divisões entre dimensões "tempora[is] ou sequencia[is]" e não sendo "etapas lineares. Cada um desses 
contextos apresenta arenas, lugares e grupos de interesse e cada um deles envolve disputas e embates" (MAINARDES, 2006, p. 50). Reafirmamos, no entanto, que em nossas análises estaremos focados nos contextos de influência, da produção de texto e da prática (figura 1), entendendo-os, como "os três contextos principais" (MAINARDES; GANDIN, 2013, p. 158) com igual importância para nossas reflexões.

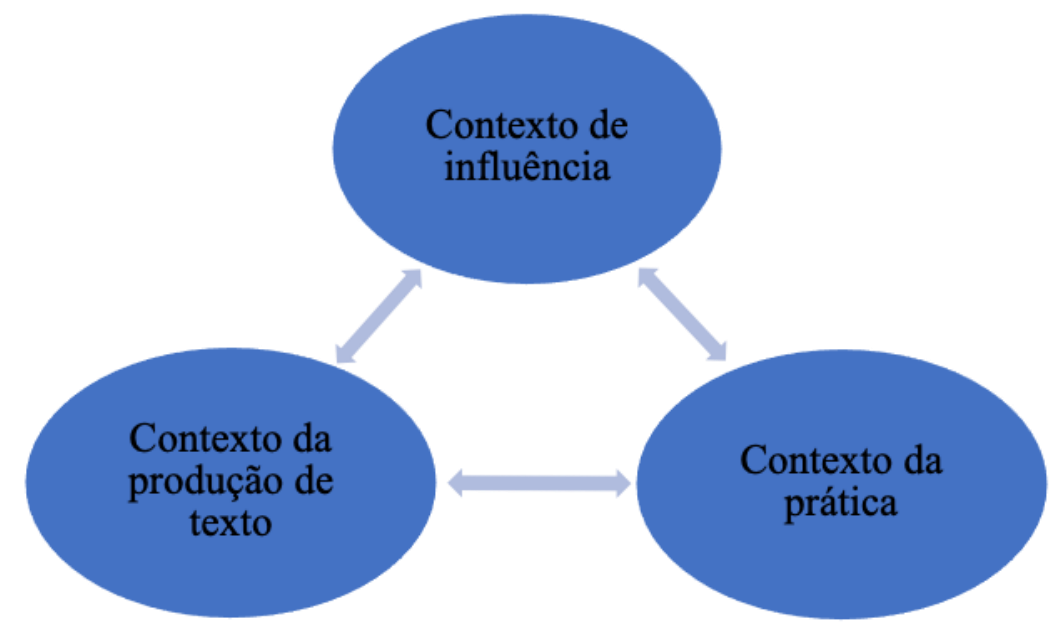

Figura 1: contextos de análise da política educacional. Fonte: adaptado de Mainardes, 2006, p. 51.

No escopo teórico apresentado e simplificadamente exposto na figura acima, parecenos ser "possível orientar a investigação de políticas educacionais" tratando do "contexto das influências (discursos, organismos, sistemas)" abordando também o "da produção dos textos políticos" e o do "contexto da prática (avaliação em larga escala e os municípios), [no qual] as políticas podem ser reconstituídas" (SANTOS, 2014, p. 265). Com efeito, podemos nos inspirar na noção de ciclo de políticas no intuito de compreender melhor o contexto estudado, partindo da premissa que ainda há muitas perguntas a serem respondidas sobre políticas e programas públicos educacionais (AVELAR, 2016). Concluindo esta seção, evidenciamos que o ciclo de políticas "envolve uma diversidade de procedimentos para coleta de dados" (MAINARDES, 2006, p. 59). No entanto, neste texto, nos focamos em analisar os documentos postos à consulta e orientação de docentes, gestores, alunado e família ligados à Rede Pública Estadual de Ensino de Minas, que passamos a descrever.

\section{A influência: a educação básica e o ensino remoto}

Revista Devir Educação, Lavras-MG. Edição Especial, p.384-408, Set./2021. 
As políticas e os programas em educação estão ligados a processos sociais complexos, nos quais se encontram imbricados valores, opções éticas e outras posições que podem movimentar o espaço escolar. A compreensão do ciclo de políticas - na abordagem analítica de políticas e programas educacionais - tem por objetivo, além de gerir a investigação, também compreender os aspectos relacionados a suas implementações, possíveis falhas e seus possíveis acertos. Para tanto, o trabalho de Ball promove o emprego de ferramentas conceituais que "podem ser trabalhadas em diferentes contextos", permitindo "que pesquisadores em educação de diferentes países utilizem suas ferramentas analíticas" (AVELAR, 2016, p. 3).

As políticas e os programas educacionais são considerados, no contexto deste trabalho, como processos sociais formulados e implementados, muitas vezes, em situações inerentes a um contexto específico de influência. Refletirmos a partir desse ponto de vista é especialmente importante durante uma pandemia inesperada que forçou a reconstrução e recriação de políticas e programas educacionais. Em específico, a produção do REANP está ligada aos conhecimentos, valores e princípios que nortearam várias ações atreladas às necessidades sanitárias em tempos de Covid-19. Analisar o REANP é pertinente não só pelo que a autoridade instituída fez, como também pelo que renunciou ante a situação da pandemia, tornando-se "ainda mais relevante para se compreender o [seu] alcance" (OLIVEIRA et al, 2021, p. 87).

$\mathrm{O}$ ano de 2020 foi palco de aceleradas rupturas sem precedentes em todas as esferas. A pandemia causada pelo vírus SARS-CoV-2 instaurou mudanças que afetaram e atravessaram a vida humana. Diante de tantas alterações, incertezas e questionamentos - transformando as relações humanas nas suas facetas sociais, econômicas, políticas etc. - foi preciso ter um novo olhar sobre as vivências e posturas de todos os cidadãos. A prioridade em reordenar e reorganizar a educação afetou acentuadamente as políticas educacionais, modificando o funcionamento do ensino para formatos remotos, suspendendo as aulas presenciais no Brasil e em vários países (UNESCO, 2021). Com base nesse cenário e dentro de sua competência, o Conselho Nacional de Educação (CNE) aprovou em plenária virtual, em 2020, o parecer CNE/CP n5/2020 (BRASIL, 2020), propondo novas diretrizes sobre a configuração dos calendários dos sistemas e redes de ensino no Brasil, sendo tais medidas abrangentes a todas 
as etapas, níveis e modalidades de ensino. Nesse mesmo parecer, discute-se a importância em "considerar as fragilidades e desigualdades estruturais da sociedade brasileira que agravam o cenário decorrente da pandemia em nosso país", apontando como aspectos mais delicados "as diferenças de proficiência, alfabetização e taxa líquida de matrícula relacionados a fatores socioeconômicos e étnico-raciais", além das condições extremamente desequilibradas econômica e socialmente de desemprego e renda, somadas àquelas de "acesso ao mundo digital por parte dos estudantes e de suas famílias". Santana e Sales (2020) apontam a dificuldade em abordar essa problemática, considerando a heterogeneidade e complexidade das circunstâncias educacionais no Brasil: sua dimensão continental, suas diferenças culturais, seus profundos desequilíbrios sociais e econômicas.

A migração abrupta do ensino presencial na direção do ensino remoto trouxe à tona desafios na elaboração do texto e na prática em consequência ao REANP ${ }^{5}$. Para que o ensino remoto fosse liberado, foi promulgada a medida provisória $\mathrm{n}^{\circ} 934$, que trata da flexibilização do calendário letivo na Educação Básica e do cumprimento de 200 dias letivos, exigindo apenas o cumprimento de 800 horas de aula ao ano. Essa medida entrou em vigor e foi convertida em Lei (n 14.040, de 18 de agosto de 2020) (BRASIL, 2020a). A partir dessa lei, o governo de cada estado poderia definir seu posicionamento em relação às aulas on-line com o objetivo de que todo o material pedagógico oferecido para aulas por meios digitais pudesse ser considerado atividade curricular. No entanto, segundo uma pesquisa do Instituto Nacional de Estudos Educacionais Anísio Teixeira (INEP), houve muitas dúvidas por parte dos governos acerca desses posicionamentos, pois não sabiam como reorganizar os calendários escolares, considerando as condições particulares de cada rede, escola, professor, estudante e sua família (BRASIL, 2021). Essas dúvidas são decorrentes, igualmente, da falta de coordenação nacional do executivo federal sobre muitos aspectos que envolvem a pandemia, não seguindo sequer o bê-á-bá proposto pela Organização Mundial de Saúde (OMS) e defendido por infectologistas sérios e pautados na Ciência: testes massivos, uso de máscaras e

\footnotetext{
${ }^{5}$ Uma dessas dificuldades constatadas foi sobre as elaborações dos textos dos programas e propostas do ensino remoto. Observamos - em pesquisas nos sites dos estados e do Distrito Federal (ver notas de rodapé $\mathrm{n}^{\circ} 8$ e 9) - que ao longo do ano de 2020 foi constante a reescrita de normas, decretos e propostas relacionados ao ensino remoto. Como já dito, tudo era muito recente, exigindo posicionamentos imediatos que, muitas vezes, precisaram ser reformulados, tornados sem efeito ou detalhados com mais cuidado.
}

Revista Devir Educação, Lavras-MG. Edição Especial, p.384-408, Set./2021. 
isolamento/distanciamento social ${ }^{6}$. De maneira específica, é possível observar que, desde o início do reordenamento e da reorganização da educação, a falta de planejamento e competência do executivo federal para tratar com o assunto dificultou muito o funcionamento das propostas e políticas educacionais (MENDES; SILVA, no prelo).

Há limitações graves, com problemas de acesso à Internet e às ferramentas tecnológicas, especialmente de professores e alunos da Educação Básica de escolas públicas. Muitos professores tiveram que se adaptar ao modelo de ensino remoto utilizando ferramentas que estavam ao seu alcance, não necessariamente as mais adequadas, dificultando a aprendizagem de muitos alunos. Segundo Bonilla et al (2020), entre as famílias mais pobres, a dificuldade de estudantes e pais está também em acompanhar as atividades propostas, principalmente em razão das desigualdades sociais existentes. Para as famílias cujos pais estão em trabalho remoto (dentre aqueles que ainda têm trabalho), o acompanhamento dos filhos tem entrado em conflito com o próprio trabalho, sendo ainda mais dificultado pelo volume de atividades profissionais e domésticas (MENDES; SILVA, no prelo).

As diferenças entre níveis e oportunidades de aprendizagem já eram relevantes no ensino regular entre alunos de classes sociais diferentes e entre alunos de escolas públicas e privadas no Brasil (BONILLA et al, 2020) e no mundo (UNESCO, 2021). Com a pandemia, somado a acentuação das diferenças sociais, vários trabalhos apontam para a perda de aprendizagem dos alunos, com o crescimento do abandono escolar, tudo isso sofrendo algum tipo de influência da falta de coordenação do Sistema Nacional de Educação pelo executivo federal (CAVALCANTE et al, 2020; COUTO et al, 2020; CONJUVE et al, 2021; OLIVEIRA et al, 2021; MENDES; SILVA, no prelo). Nesse sentido, Perrenoud (2000) considera que a preocupação em ajustar o ensino às condições dos alunos e professores não surge apenas no respeito às pessoas e ao bom senso pedagógico. Tal preocupação faz parte de uma certa exigência de igualdade. Segundo o autor, a indiferença às diferenças transforma as desigualdades iniciais - por questões culturais, sociais e econômicas - em desigualdades de aprendizagem e, por consequência, desigualdades sociais, culturais e econômicas do alunado das camadas populares ao longo de suas vidas.

6 Para saber mais consulte https://www.who.int/es/emergencies/diseases/novel-coronavirus2019? adgroupsurvey=\% 7badgroupsurvey\%7d\&gclid=EAIaIQobChMImKOmLXo8QIVD4bICh2pzQrTEAAYAiAAEgLucvD_BwE.

Revista Devir Educação, Lavras-MG. Edição Especial, p.384-408, Set./2021. 
Com o ensino presencial tornando-se uma alternativa de alto risco, foi preciso buscar meios para o seu desenvolvimento de forma remota e mais segura, mesmo sem a coordenação do MEC ou outras instâncias do executivo federal. Por um lado, é corriqueira na literatura a discussão sobre como as políticas e os programas educacionais relacionados ao emprego de tecnologias digitais nas escolas não superaram os obstáculos atrelados à falta de estrutura, de equipamentos adequados e de preparação/capacitação dos professores no manuseio de suportes tecnológicos (ALMEIDA; VALENTE, 2016; OLIVEIRA et al, 2021; MENDES; SILVA, no prelo). Por outro lado, com “[ ...] a suspensão das atividades presenciais" gerou-se "a obrigatoriedade dos professores e estudantes migrarem" para atividades on-line, na tentativa de transferir e transpor - muitas vezes, infelizmente, com pouco êxito "metodologias e práticas pedagógicas típicas dos territórios físicos de aprendizagem" em relação ao "que se tem apelidado de ensino remoto de emergência" (MOREIRA; SCHLEMMER, 2020, p. 07). Vejamos com mais detalhes como, nos textos do REANP, foram colocadas ações para a prática do cotidiano escolar a partir dessas séries de influências descritas.

\section{O texto e a prática: ensino remoto emergencial mineiro}

Neste artigo, naquilo que concerne às reflexões acerca do REANP - um programa emergencial voltado para a implementação do ensino remoto -, são fundamentais as relações entre as noções sobre a política como texto e como prática. Segundo Mainardes (2006, p. 59), os textos dizem "respeito aos documentos oficiais" que, mesmo depois de publicados, devem ser interpretados como "produtos inacabados com múltiplas possibilidades de interpretação e entendimento", a mercê de "embates, discussões, conflitos que são decodificados e interpretados de acordo com os atores envolvidos". Com essa forma de ver, tais aspectos são percebidos não só nos textos das políticas e dos programas públicos. Igualmente estão presentes em seus processos de implementação na prática. Temos os exemplos das políticas e dos programas que propõem textualmente o emprego das tecnologias digitais no ensino, no entanto, aquilo proposto não se materializa no cotidiano e na prática escolares (ALMEIDA; VALENTE, 2016; OLIVEIRA et al, 2021). Mesmo assim, entendemos que é o texto que leva a propor determinadas estratégias e mecanismos, sendo uma modalidade primária de análise,

Revista Devir Educação, Lavras-MG. Edição Especial, p.384-408, Set./2021. 
"pois as políticas são escritas, enquanto que" os outros contextos estão mais relacionados às ações e práticas cotidianas, incluindo "o fazer [das] coisas" (MAINARDES; MARCONDES, 2009, p. 305). Ponderamos igualmente que "políticas [...] educacionais [...] são pensadas e em seguida escritas" tendo como parâmetro as "melhores escolas possíveis [...], com pouco reconhecimento de variações de contexto, em recursos ou em capacidades locais" (MAINARDES; MARCONDES, 2009, p. 306). Levando em conta esses aspectos a nortearem nossas reflexões, abordaremos com mais detalhes o REANP nos contextos de produção do texto e da prática.

A Secretaria de Estado da Educação de Minas Gerais (SEE/MG) institucionalizou o REANP/MG em 17 de abril de 2020, por meio da Resolução SEE nº 4310/2020. O REANP propõe que os processos sejam executados essencialmente por meios digitais, indicando a necessidade de se manter e reforçar a interação do professor com os alunos e entre os alunos, por meio do uso de tecnologias digitais e, em algumas situações, empregando materiais impressos ${ }^{7}$. Segundo a mesma resolução, o REANP

constitui-se de procedimentos específicos, meios e formas de organização das atividades escolares obrigatórias destinadas ao cumprimento das horas letivas legalmente estabelecidas, à garantia das aprendizagens dos estudantes e ao cumprimento das Propostas Pedagógicas, nos níveis e modalidades de Ensino, ofertados pelas escolas estaduais (MINAS GERAIS, 2020).

Ao longo de 2020 e 2021, foram criadas e reformuladas "as ferramentas para você estudar em casa com segurança neste período de isolamento social" (grifo nosso), constituindo, ao mesmo tempo, o REANP. No site Estude em $\mathrm{Casa}^{8}$ descreve-se os materiais/ferramentas do REANP propostos pela SEE/MG. Na página inicial do site, a forma de apresentação do discurso sobre as chamadas "ferramentas" tem como interlocutor o aluno - por isso o uso do pronome pessoal você grifado acima. Encontramos aí uma técnica de endereçamento e captura dos sujeitos alvo (os estudantes) na busca de torná-los um público enformado pelos objetivos do documento (ELLSWORTH, 2001). No site Estude em Casa,

\footnotetext{
${ }^{7}$ Segundo Oliveira et al (2021, p. 94), ao analisarem o funcionamento do REANP, argumentam que "para os estudantes que não possuem acesso à Internet" as escolas deverão "assegurar que o material impresso seja disponibilizado ao estudante. Com o apoio das 47 Superintendências Regionais de Ensino [de Minas Gerais], caberá às escolas identificar como o material chegará a todos os estudantes".

${ }^{8}$ Para saber mais consulte https://estudeemcasa.educacao.mg.gov.br/inicio.
} 
versão 2021, são apresentadas as seguintes ferramentas a explicarem e constituírem o REANP mineiro:

a) Programa de Estudos Tutorados (PET): consiste em apostilas mensais que reúnem atividades, orientações de estudos e conteúdos (da Educação Infantil ao Ensino Médio) de cada componente curricular, sendo elaboradas com base no Currículo Referência de Minas Gerais (CRMG) e na BNCC.

b) Se Liga na Educação: programa transmitido pela Rede Minas, de segunda a sexta-feira, das 7:00 às 12:30. São quatro horas de aulas gravadas, além de um tempo ao vivo (11h15 às 12h30), no qual os estudantes poderão interagir, por meio das redes sociais, com os professores no estúdio.

c) Conexão Escola: é um aplicativo para celular apresentado como mais uma forma de acesso ao PET, aos materiais de orientação, às aulas síncronas com os professores, às aulas on-line gravadas (via Google Mett) e às aulas da Rede Minas. Ao longo de 2020 apresentou vários problemas de funcionalidade (OLIVEIRA et al, 2021) e, em 2021, foi reformulado e renomeado de "Conexão Escola 2.0" . Vem acompanhado pelo documento Guia Prático (Aplicativo Conexão Escola) que apresenta informações acerca do uso pelo público-alvo (professores, alunos e gestores). Nele, disponibiliza-se o endereço de um curso autoformativo, on-line, com carga horária de 60 horas (Google for Education: recursos e possibilidades $)^{10}$, considerado essencial na utilização eficaz e eficiente de todas as ferramentas disponíveis na plataforma Google for Education para acesso por computadores e aplicativos de celular.

d) Documentos Orientadores: foram elaborados com o intuito de trazer a baila algumas medidas didático-pedagógicas e normativas tomadas para a consolidação do REANP, sendo constituídos pelos seguintes documentos: 1) Guia prático para o Início do Ano Letivo 2021; 2) Documento Orientador REANP (versões 2020 e 2021); 3) Educação em Tempo Integral; 4) Ensino Fundamental e Médio; 5) Educação Profissional e Curso Normal de Nível Médio.

e) Fortalecimento da Aprendizagem: são documentos balizadores para gestores, professores e alunos com atividades relacionadas aos cuidados (de aprendizagem, emocional, didático-

\footnotetext{
${ }^{9}$ Informações no site https://estudeemcasa.educacao.mg.gov.br/inicio. Acesso em: 27 jun. 2021.

${ }^{10}$ Com o objetivo de preparar os professores no emprego das ferramentas propostas, a SEE/MG ofertou cursos sobre a utilização das tecnologias digitais no ensino escolar. Para saber mais consulte https://escoladeformacao.educacao.mg.gov.br/index.php/inscricoes-abertas/341-curso-google-foreducation-recursos-e-possibilidades-t2. Acesso em: 28 jun. 2021.
}

Revista Devir Educação, Lavras-MG. Edição Especial, p.384-408, Set./2021. 
pedagógico) com os atores da escola, especialmente o alunado, como também orientações relativas ao cumprimento do calendário escolar e da carga horária anual estabelecidos pelo CNE (BRASIL, 2020). Fazem parte dessa ferramenta os documentos: 1) Escola Acolhedora; 2) Acolhimento remoto sem uso de conectividade; 3) Reforço Escolar e seu anexo; 4) Os Melhores Sábados Letivos da sua Vida e seu anexo; 5) Intervenção Pedagógica e seu anexo ${ }^{11}$. f) Se liga na Libras: apresenta vídeos em libras tratando de vários conteúdos escolares e aspectos da cultura da Língua de Sinais, assim como sua história, o contexto que os surdos vivem e suas particularidades.

g) Projeto Vamos aprender: é um projeto do Conselho Nacional de Secretários de Educação (CONSED) e da União Nacional dos Dirigentes Municipais de Educação (UNDIME), com parceria e apoio da Fundação Roberto Marinho, da Fundação Lemann, do Itaú Social, dentre outras organizações da sociedade civil. Oferta programas televisivos de 30 a 40 minutos para todas as idades de estudantes, do Ensino Infantil ao Ensino Médio, elaborados com base na $\mathrm{BNCC}^{12}$.

i) Legislações, dúvidas comuns e contato/suporte: é a ferramenta que reúne várias informações concernentes ao desenvolvimento do REANP. Em "legislações" temos deliberações, Decretos e outros documentos publicados no Diário Oficial do Estado. Em "dúvidas comuns", encontram-se as respostas mais corriqueiras, questões sobre as ferramentas disponibilizadas, suas características e outras tratativas do regime de teletrabalho do servidor. Para demais informações solicita-se que o usuário acesse o "Fale Conosco". O "Contato/Suporte" é um formulário Google a ser preenchido com os dados do interessado e sua solicitação acerca de questões atreladas ao PET, aos slides trabalhados em aula e às vídeoaulas.

Em algum momento entre 27 de junho a 13 de julho foi acrescentada a ferramenta "Prêmio Escola Transformação" que "tem o objetivo de reconhecer publicamente as práticas e experiências exitosas das unidades escolares no processo de melhoria da qualidade do ensino". No entanto, ao lermos o material explicativo não encontramos nenhuma relação

11 Informações em https://estudeemcasa.educacao.mg.gov.br/fortalecimento-das-aprendizagens. Acesso em: 27 jun. 2021.

12 Informações em https://estudeemcasa.educacao.mg.gov.br/projeto-vamos-aprender e https://vamosaprender.tv.br/sobre/. Acessos em: 29 jun. 2021.

Revista Devir Educação, Lavras-MG. Edição Especial, p.384-408, Set./2021. 
direta ou indireta com o REANP/MG ${ }^{13}$. Em um exercício de imaginação, supomos que experiências relacionadas ao Regime mineiro poderão/deverão concorrer ao Prêmio. Igualmente, é possível imaginar que outros mecanismos explicativos e orientadores foram empregados e precisam ser identificados (por exemplo, explicações elaboradas pelas Superintendências Regionais de Ensino e/ou divulgadas por grupos de WhatsApp e e-mails e/ou tratadas em reuniões on-line específicas com gestores e professores).

Um possível problema para o sucesso do REANP está no fato de que muitas políticas e muitos programas exigem dos professores um enorme esforço de entendimento em abancar palavras de textos e transformá-las em práticas, em algo que seja viável dentro das complexidades do ambiente da sala de aula. Frequentemente, esses mesmos professores são confrontados, e ao mesmo tempo, com outras políticas e/ou demandas diferentes, que podem ser ainda mais desafiadoras, por tratarem também de questões que envolvem trabalho com recursos e infraestruturas limitados, sendo o caso da pandemia e a necessidade de isolamento que impôs. Ademais, "os textos políticos são com frequência documentos muito mal escritos, os quais criam dificuldades enormes para aqueles que devem fazer algo com eles" (AVELAR, 2016, p. 7). E ainda mais, mostrando como as dificuldades podem se sobrepor, somando efeitos perversos sobre o ensino, cotidianamente durante a pandemia diferentes mídias e pesquisas de diversas fontes evidenciaram realidades mais deficitárias de acesso às tecnologias digitais por professores e estudantes de escolas públicas em relação aos das escolas privadas. Mostram, da mesma forma, as dificuldades de formação e de condições de trabalho dos docentes em contextos de isolamento para atuarem com as tecnologias digitais questão comum em instituições públicas e privadas, porém, mais acentuada nas primeiras. Não podemos esquecer que o trabalho docente tornou-se ainda mais domiciliar (pois já o era antes da pandemia), misturando e confundindo-se com a vida familiar e privada (MENDES; SILVA, no prelo).

Por tudo isso, podemos imaginar as dificuldades relacionadas ao êxito de algo praticável por professores e gestores a partir das ferramentas do REANP. Os professores e gestores tiveram pouco tempo na assimilação dos textos dessas ferramentas, sendo essas apresentadas com problemas de organização didático-pedagógica no entendimento de suas funções. Em nossas pesquisas, constatamos que as secretarias de educação enfrentaram

${ }_{13}$ Para saber mais consulte https://estudeemcasa.educacao.mg.gov.br/premio-escola-transformacao. Acesso em: 13 jul. 2021.

Revista Devir Educação, Lavras-MG. Edição Especial, p.384-408, Set./2021. 
desafios ao traçarem estratégias acerca das políticas educacionais com o intuito da realização do ensino remoto. Muitas secretarias de educação de estados e municípios adotaram, desde março de 2020, regimes de estudos não presenciais - uma versão do ERE focada na Educação Básica e, em vários estados e municípios, com denominações similares ${ }^{14}$ - e, com isso, traçaram estratégias e meios para que o ensino remoto ocorresse diante das adversidades. Mesmo com os esforços constatados, em uma primeira sondagem feita em todos os sites das Secretarias de Estado da Educação dos estados e do Distrito Federal, observamos uma certa dificuldade na organização e divulgação dos materiais, das estratégias e dos procedimentos sobre o ensino remoto no período pandêmico. Em vários deles, a disposição dos materiais mais parece um emaranhado de hiperlinks, publicizados no site no momento que foram produzidos, não tendo uma lógica de ordenamento pedagógico de acesso ${ }^{15}$. Em outros, o ensino remoto se confunde com noções de ensino híbrido, com duvidoso lastro teórico e conceitual concernente ao assunto (MENDES; SILVA, no prelo). Infelizmente, nos materiais

${ }^{14} \mathrm{O}$ termo Regime Especial de Atividades Não Presenciais (REANP) não consta em nenhum documento do CNE ou do MEC. Em uma Nota de Esclarecimento, de 18 de março de 2020, o CNE autoriza "a realização de atividades a distância" em toda a Educação Básica, incluindo Educação profissional, EJA e Educação Especial (BRASIL, 2020b). Na Resolução CNE/CP no 5/2020 consta "regimes especiais de ensino que compreendam atividades não presenciais mediadas ou não por tecnologias digitais de informação e comunicação" (BRASIL, 2020, grifos nossos). Em uma página do CONSED (https://consed.info/ensinoremoto/), atualizada em 13 de julho de 2021, e nos respectivos sites das secretarias, consta que os estados de Alagoas (Regime Especial de Atividades Escolares Não Presenciais - REAENP), do Ceará (Regime Especial não Presencial), do Espírito Santo (Atividades Pedagógicas Não Presenciais), de Goiás (Regime Especial de Aulas não Presenciais - REANP), de Minas Gerais (Regime Especial de Atividades Não Presenciais - REANP), da Paraíba (Regime Especial de Ensino) empregam termos similares, com características de organização relacionadas com atividades on-line, televisivas, impressas e, algumas vezes, com algum tipo de referência a noções diversas de hibridismo no ensino.

${ }^{15}$ Esse levantamento foi realizado entre 22 de março a $1^{\circ}$ de abril, nos seguintes endereços: Acre (https://educ.see.ac.gov.br/pagina/see-principal; Alagoas (http://www.educacao.al.gov.br/); Amapá (https://seed.portal.ap.gov.br/); Amazonas (http://www.seduc.am.gov.br/); Bahia http://www.educacao.ba.gov.br/); Ceará (https://www.seduc.ce.gov.br/); Distrito Federal (http://www.educacao.df.gov.br/); Espírito Santo (https://sedu.es.gov.br); Goiás (https://site.educacao.go.gov.br/); Maranhão (https://www.educacao.ma.gov.br/?site=1); Mato Grosso (http://www.seduc.mt.gov.br/); Mato Grosso do Sul (https://www.sed.ms.gov.br/); Minas Gerais (https://www2.educacao.mg.gov.br/); Pará (http://www.seduc.pa.gov.br/); Paraíba (https://paraiba.pb.gov.br/diretas/secretaria-da-educacao-e-da-ciencia-e-tecnologia); Paraná (http://www.educacao.pr.gov.br/); Pernambuco (http://www.educacao.pe.gov.br/portal/); Piauí (https://www.seduc.pi.gov.br/); Rio de Janeiro (https://www.seeduc.rj.gov.br/); Rio Grande do Norte (http://www.educacao.rn.gov.br/); Rio Grande do Sul (https://educacao.rs.gov.br/inicial); Rondônia (http://www.rondonia.ro.gov.br/seduc/); Roraima (http://www.educacao.rr.gov.br/); Santa Catarina (https://www.sed.sc.gov.br/); São Paulo (https://www.educacao.sp.gov.br/); Sergipe (https://www.seed.se.gov.br/oficial.asp); Tocantins (https://seduc.to.gov.br/).

Revista Devir Educação, Lavras-MG. Edição Especial, p.384-408, Set./2021. 
encontrados nos sites relacionados ao REANP mineiro, as mesmas dificuldades de organização para dar sentido didático-pedagógico ao material foram observadas.

Isso posto, compreendemos que os caminhos de tradução das políticas e dos programas em prática é um processo complexo, pois inicialmente eles se configuram em um texto e devem ser transformados em ações. Esse processo é algo difícil e desafiador, pois cada local em que o REANP foi e está sendo implementado apresenta suas particularidades e necessidades, como também há a questão de interpretação e criatividade por cada um que o utiliza. A escrita de propostas e políticas para escolas utópicas não pode ser simplesmente interpretada. Ela passa por um processo completo de tradução, negociação e análise, sendo colocada (ou não colocada) em prática por ações dos professores e gestores, com formações diferentes e em contextos diversos (BALL, 2020), que, no caso do REANP, devem ainda fazer um grande esforço de entendimento sobre o que realmente está sendo proposto com e nas ferramentas divulgadas e oportunizadas.

Muitas vezes, esses tipos de propostas ou mudanças de política educacional desconsideram que "os profissionais que atuam no contexto da prática [escolas, por exemplo] não enfrentam os textos políticos como leitores ingênuos, eles vêm com suas histórias, suas experiências, seus valores e seus propósitos” (BOWE et al., 1992, p. 22). Isso é especialmente importante se considerarmos as dificuldades estruturais (acesso a máquinas, conexões e assistência técnica minimamente satisfatórias), econômicas (salários indignos ${ }^{16}$ para a vida cotidiana, sendo impensado a compra de máquinas mais adequadas para o trabalho pedagógico) e de formação (cursos de formação de professores que não tratam ou tratam superficialmente do emprego das tecnologias digitais na educação) que os profissionais da educação passam e/ou convivem quando encaram o uso de tecnologias digitais nas escolas. Além disso, somando-se às diferenças existentes - com formas diversas e desequilibradas de acesso e entendimento técnico das tecnologias digitais - entre professores que atuam em escolas de cidades de pequeno, médio ou grande porte ${ }^{17}$, evidencia-se que "políticas serão

\footnotetext{
${ }^{16}$ Em Minas Gerais, com base em dados de 2020, “o salário de Professor da Educação Básica (PEB) varia entre $R \$ 1.455,30$ e $R \$ 2.135,64$, para jornadas de trabalho de 24 horas. A remuneração média do Diretor de Escola é R\$ 6.741,48. O Especialista em Educação Básica (EEB), responsável pelo trabalho de orientação, implementação e avaliação do processo de ensino e aprendizagem nas escolas, tem remuneração média de R \$ 3.481,20" (OLIVEIRA et al, 2021, p. 91).

${ }^{17}$ Minas Gerais tem uma população estimada de 21 milhões de pessoas, sendo "o segundo estado mais populoso, [com] o maior número de cidades [...]", constituindo-se em "uma das regiões mais heterogêneas do país", coexistindo "regiões dinâmicas, modernas e com elevados indicadores
} 
[re]interpretadas diferentemente, uma vez que histórias, experiências, valores, propósitos e interesses são diversos". Por todos esses motivos - com o ensino sendo reestruturado a partir do isolamento social, de maneira remota - acentua-se ainda mais "que os autores dos textos políticos não [têm como] controlar os significados de seus textos. Partes podem ser rejeitadas, selecionadas, ignoradas, deliberadamente mal-entendidas, réplicas podem ser superficiais etc." (BOWE et al., 1992, p. 22) quando se encontram no contexto da prática e com tantas variáveis a interferir no trabalho docente.

\section{Considerações finais}

A pandemia está sendo um grande contexto de influência, afetando as políticas e os programas de ensino no Brasil e no mundo. No cenário que se apresentou, muitas mudanças foram necessárias para que a aprendizagem escolar não ficasse estagnada. $\mathrm{O}$ ensino remoto começou como uma alternativa segura às aulas presenciais. Contudo, esse começo foi abarcado por muitos desafios e muitas dificuldades por todos que estavam envolvidos no processo de implementação e funcionamento do REANP. Podemos perceber que, mesmo diante de ações tomadas pelos governos estaduais e pelas secretarias de educação, ainda existem vários problemas que persistiram no ensino remoto ofertado pelas escolas brasileiras. Acrescenta-se ao cenário das incertezas, o fato de não sabermos por quanto tempo teremos que nos manter isolados ou se outras endemias ou pandemias dessa natureza nos assolarão novamente, pois são acontecimentos que acompanham a história humana desde a Grécia Antiga (SOZINHO, 2021). Considerando as limitações de acesso à Internet e aos aparelhos digitais - somado ao tempo que alunos e professores ainda terão que enfrentar atividades essencialmente digitais -, Bonilla et al (2020, p. 12) já apontavam que "o contexto da pandemia não pode[ria]" ser motivo de se propor, "de forma desorganizada e imediatista, [...] arranjos para que gestores, professores e alunos" pudessem empregar "as tecnologias digitais,

socioeconômicos e localidades empobrecidas e pouco desenvolvidas". O Índice de Desenvolvimento Humano Municipal (IDH-M) das "regiões sudoeste, sul, sudeste e na Região Metropolitana de Belo Horizonte" - esta última, onde basicamente são pensadas as políticas públicas para todo o estado - são os mais elevados. "Por outro lado, as mesorregiões localizadas nas regiões norte, noroeste e nordeste são as menos desenvolvidas e, portanto, as mais desiguais. Ainda que não respondam por um número expressivo de habitantes, metade da população dessas regiões vive em situação de pobreza e extrema pobreza" (OLIVEIRA et al, 2021, p. 89).

Revista Devir Educação, Lavras-MG. Edição Especial, p.384-408, Set./2021. 
como se fossem ações absolutamente normais no cotidiano de todos". Portanto, para além da educação ampla e de qualidade dos alunos, temos que analisar as condições concretas dos professores e estudantes, considerando questões materiais, emocionais (ansiedade e autoflagelação, por exemplo) e de formação (CONJUVE et al, 2021).

No contexto da produção do texto, ressaltamos que o REANP - como um programa de ensino remoto - não se diferencia em termos metodológicos do ensino presencial (MOREIRA; SHLEMMER, 2020). A diferença está nas formas de adaptação desse ensino presencial que passa a ser em regime de isolamento e distanciamento social. Embora haja um distanciamento geográfico, privilegia-se o compartilhamento da aula, ocorrendo em um tempo síncrono, seguindo princípios do ensino presencial. Porém, podemos destacar que muitos momentos assíncronos aconteceram. O ensino remoto pautado em tecnologias digitais, aulas on-line, plataformas e Ambientes Virtuais de Aprendizagem (AVA) foram as possibilidades acolhidas em muitas políticas e programas educacionais no período pandêmico e trabalhadas pelas escolas como mecanismos de ensino e aprendizagem. No entanto, infelizmente essas estratégias vêm trazendo grandes desafios, pois com o REANP, os professores mineiros tiveram que se reinventar, aprender e reconstruir suas formas de ensino. Além disso, há o desafio de formular aulas e conteúdos que possam chegar a todos os alunos de forma igualitária, sendo o acesso à Internet uma grande barreira para se superar esse desafio. Como demonstramos ao longo do artigo, o contexto da produção do texto não acompanha a realidade cotidiana, sem sombra de dúvidas, mais difícil do que aquela descrita nas ferramentas do REANP.

No contexto da prática, o ensino escolar teve um reinício com muitos questionamentos e dificuldades. Parte considerável dos docentes não estava preparada para ter as tecnologias digitais como recurso central do desenvolvimento de suas aulas. Além disso, muitos alunos não possuíam acesso às tecnologias necessárias à integração dos mecanismos on-line de ensino em seus cotidianos. Outros tantos - mais afortunados social e economicamente -, contanto com aparelhos e Internet adequados, tinham também familiares a acompanhá-los mais de perto, mesmo que isso tenha acarretado a somatória de demandas profissionais e domésticas (COUTO et al, 2020; MENDES; SILVA, no prelo). Antes da pandemia, o foco era conectar escolas com banda larga no intuito de terem acesso a atividades pedagógicas online, sendo o acompanhamento feito essencialmente pelos docentes. Com a pandemia, essa 
necessidade tomou outra dimensão, passando os estudantes a terem a necessidade de se conectarem para terem acesso ao ensino em espaços extraescolares, com a necessidade do acompanhamento familiar direcionado ao aumento de sucesso da aprendizagem (CAVALCANTE et al, 2020).

Ao analisarmos o REANP, à luz do ciclo de políticas, concluímos que o ensino escolar, antes da pandemia, apresentava dificuldades que se acentuaram durante a pandemia. No momento da crise sanitária, com o isolamento/distanciamento social, ficaram gritantes os problemas em relação à formação de professores, à valorização da profissão docente (estamos falando de salários minimamente dignos) e condições materiais mais adequadas (estamos falando de melhores escolas) para o trabalho com as tecnologias digitais na educação. No póspandemia, se as políticas públicas continuarem a dar a mesma atenção periférica do antes e do durante a pandemia, em uma possível nova crise sanitária, caminharemos a passos mais largos na direção da barbárie social, independente se voltarmos a ter um executivo federal ineficaz, incompetente, despreparado, corrupto e ideologicamente fundamentalista, conservador e autoritário.

\section{Referencial bibliográfico}

ALMEIDA, M. E. B.; VALENTE, J. A. Políticas de tecnologia na educação brasileira. São Paulo: CIEB, 2016.

AVELAR, M. Entrevista com Stephen J. Ball. Education policy analysis archives, v. 4, n. 4, p. 1-18, 2016. DOI: http://dx.doi.org/10.14507/epaa.24.2368.

BALL, S. Educação Global S. A.: novas redes de políticas e o imaginário neoliberal. Ponta Grossa: UEPG, 2020.

BALL, S. J.; BOWE, R. Subject departments and the 'implementation' of National Curriculum policy: an overview of the issues. Journal of Curriculum Studies, v. 24, n. 2, p. 97-115, 1992. DOI: https://doi.org/10.1080/0022027920240201.

BALL, S. J. Educational reform: a critical and post-structural approach. Buckingham: Open University Press, 1994.

BONILLA, H. S.; PRETTO, N. L. SENA, I. P. F. S. Educação em tempos de pandemia: reflexões sobre as implicações do isolamento físico imposto pela COVID-19. Edição dos autores.

Salvador,

2020.

Disponível

em: 
https://blog.ufba.br/gec/files/2020/05/GEC_livro_final_imprensa.pdf. Acesso em: 28. mar. 2021.

BOWE, R.; BALL, S. J.; GOLD, A. Reforming education and changing schools. London: Routledge, 1992.

BRASIL. MEC. Conselho Nacional de Educação. Parecer CNE/CP $\mathbf{n}^{\mathbf{0}}$ 05/2020: reorganização do calendário escolar em razão da pandemia da COVID-19. Brasília: 28 de abr. 2020. Disponível em: http://portal.mec.gov.br/index.php?option=com_docman\&view=download\&alias=14511pcp005-20\&category_slud=marco-2020-pdf\&Itemid=30192. Acesso em: 09 jul. 2021.

BRASIL. Presidência da República. Lei $\mathbf{n}^{\mathbf{0}}$ 14.040, de 18 de agosto de 2020: estabelece normas educacionais excepcionais a serem adotadas durante o estado de calamidade pública reconhecido pelo Decreto Legislativo n ${ }^{\circ}$ 6, de 20 de março de 2020. Brasília: 18 ago. 2020a. Disponível em: http://www.planalto.gov.br/ccivil_03/_ato2019-2022/2020/Lei/L14040.htm. Acesso em: 15 mar. 2021.

BRASIL. Conselho Nacional de Educação. Nota de esclarecimento. Brasília: 18 de mar. 2020b. Disponível em: http://consed.org.br/media/download/5e78b3190caee.pdf. Acesso em: 15 jul. 2021.

BRASIL. INEP. Pesquisa resposta educacional à pandemia de COVID-19. Brasília: INEP, 2021. Disponível em: https://www.gov.br/inep/pt-br/areas-de-atuacao/pesquisas-estatisticas-eindicadores/censo-escolar/pesquisas-suplementares/pesquisa-covid-19. Acesso em: 09 jul. 2021.

CASTIONI, R.; MELO, A. A. S.; NASCIMENTO, P. M. Universidades federais na pandemia da Covid-19. Ensaio, v. 29, n. 111, abr./jun. 2021. DOI: https://doi.org/10.1590/s0104$\underline{40362021002903108 .}$.

CAVAlCANTE, A. L. L.; DOURADO, A. C. S.; MARTINS, A. Educar em tempos de incertezas: a implementação do ensino remoto na rede municipal de Floriano-Piauí. Revista Dialogia, n. 36, p. 73-85, set./dez. 2020. DOI: https://doi.org/10.5585/dialogia.n36.18619.

CONJUVE e parceiros. Juventudes e a Pandemia do Coronavírus. Brasília, 2021. Disponível em:

https://mk0atlasdasjuve5w21n.kinstacdn.com/wpcontent/uploads/2021/06/JuventudesEPande mia2_Relatorio_Nacional_20210607.pdf. Acesso em: 13 jul. 2021.

COUTO, E. S.; COUTO, E. S.; CRUZ, I. M. P. \#Fiqueemcasa: educação na pandemia da covid-19. Interfaces Científicas, v. $8, \quad$ n. $3, \quad$ p. 200-217, 2020. DOI: https://doi.org/10.17564/2316-3828.2020v8n3p200-217.

DREYFUS, H. L.; RABINOW, P. Michel Foucault: uma trajetória filosófica. Rio de Janeiro: Forense Universitária, 1995. 
ELLSWORTH, E. Modo de endereçamento. In: SILVA, T. T. (Org.). Nunca fomos humanos. Belo Horizonte: Autêntica, 2001.

HODGES, C.; MOORE, S. LOCKEE, B. TRUST, T. BOND, A. The Difference Between Emergency Remote Teaching and Online Learning. Educause Review, 2020. Disponível em: https://er.educause.edu/articles/2020/3/the-difference-between-emergency-remote-teachingand-online-learning\#fn3 . Acesso em: 15 jul. 2020.

LIMA, L. F.; SOUZA, B. S.; LUCE, M. B. A abordagem do ciclo de políticas nos programas de pós-graduação brasileiros: um mapa das teses e dissertações. Revista de Estudios Teóricos y Epistemológicos en Política Educativa, v. 3, p. 1-29, 2018. DOI: https://doi.org/10.5212/retepe.v.3.008.

MAINARDES, J. Abordagem do ciclo de políticas: uma contribuição para a análise de políticas educacionais. Revista Educação e Sociedade, v. 27, n. 94, p. 47-69, jan./abr. 2006. DOI: https://doi.org/10.1590/S0101-73302006000100003.

MAINARDES, J.; MARCONDES, M. I. Entrevista com Stephen J. Ball: um diálogo sobre justiça social, pesquisa e política educacional. Educação \& Sociedade, v. 30, n. 106, p. 303318, jan./abr. 2009. DOI: https://doi.org/10.1590/S0101-73302009000100015.

MAINARDES, J.; GANDIN, L. A. A Abordagem do ciclo de políticas como epistemetodologia. In: TELLO, C.; ALMEIDA, M. L. P. (Orgs.). Estudos epistemológicos no campo da pesquisa em política educacional. Campinas: Mercado de Letras, 2013.

MENDES, C. L.; SILVA, R. A panaceia do ensino híbrido: o público, o privado e o futuro da educação. Currículo sem Fronteiras, no prelo.

MINAS GERAIS. Secretaria de Estado de Educação. Resolução see $\mathbf{n}^{\mathbf{0}}$ 4310/2020: dispõe sobre normas para a oferta de regime especial de atividades não presenciais. Cidade Administrativa: 17 abr. 2020.2 Disponível https://www2.educacao.mg.gov.br/images/documentos/Resolucao\%20SEE_N_4310.pdf.

Acesso em: 13mar. 2021.

MOREIRA, J. A; SCHLEMMER, E. Por um novo conceito e paradigma de educação digital $\begin{array}{llllll}\text { online. } & \text { Revista } & \text { UFG, } & \text { v. } & 20, & 2020\end{array}$ https://www.revistas.ufg.br/revistaufg/article/view/63438.

OliveIRA, B. R.; OliveIRA, A. C. P.; JORGE, G. M. S.; COELHO, J. I. F. Implementação da educação remota em tempos de pandemia. RIAEE, v. 16, n.1, p. 84-106, jan./mar. 2021. DOI: https://doi.org/10.21723/riaee.v16i1.13928.

PERRENOUD, P. Pedagogia diferenciada. Porto Alegre: Artmed, 2000.

RONDINI, C. A.; PEDRO, K. M.; DUARTE, C. S. Pandemia da covid-19 e o ensino remoto emergencial. Interfaces Científicas, v. 10, n. 1, p. 41-57, 2020. DOI: https://doi.org/10.17564/2316-3828.2020v10n1p41-57.

Revista Devir Educação, Lavras-MG. Edição Especial, p.384-408, Set./2021. 
ROSA, S. S. Uma introdução às ideias e às contribuições de Stephen J. Ball para o tema da implementação de políticas educacionais. Revista de Estudios Teóricos y Epistemológicos en Política Educativa, v. 4, p. 1-17, 2019. DOI: https://doi.org/10.5212/retepe.v.4.004.

ROSE, N. Inventing our selves. London: Cambridge, 1996.

SAMPAIO, R. M. Práticas de ensino e letramentos em tempos de pandemia da COVID-19. Research, Society and Development, v. 9, n. 7, 2020. DOI: https://doi.org/10.33448/rsdv9i7.4430.

SANTANA, C. L.; SALES, K. M. Aula em casa: educação, tecnologias digitais e pandemia COVID-19. Revista Interfaces Científicas, v. 10, n. 1, p. 75-92, 2020. DOI: https://doi.org/10.17564/2316-3828.2020v10n1p75-92.

SANTOS, A. P. Abordagem do ciclo de políticas e suas contribuições para análise da política de avaliação em larga escala. Meta: Avaliação, v. 6, n. 18, p. 263-280, set./dez. 2014. DOI: http://dx.doi.org/10.22347/2175-2753v6i18.391.

SOZINHO, C. As pandemias e endemias na história da humanidade: balanço histográfico. KULONGESA, v. 3, n. 1, p. 25-32, 2021. Disponível em: https://kulongesa.ispls.ao/index.php/kulongesa-tes/article/view/237. Acesso em: 17 jul. 2021.

STREMEL, S. MAINARDES, J. A constituição do campo da política educacional no brasil como objeto de estudo. Revista Educação e cultura contemporânea, v. 16, n. 46, p. 31-46, 2019. DOI: HTTP://DX.DOI.ORG/10.5935/2238-1279.20190097.

UNESCO. Supporting learning recoveryone year into COVID-19: the global education coalition in action. Paris: UNESCO, 2021. Disponível em: https://unesdoc.unesco.org/ark:/48223/pf0000376061. Acesso em: 20 maio 2021.

Recebido em: 22/07/21

Aprovado em: 26/08/21

Revista Devir Educação, Lavras-MG. Edição Especial, p.384-408, Set./2021. 